\section{Saúde e ambiente no Brasil: desenvolvimento, território e iniqüidade social}

\author{
Health and environment in Brazil: development, \\ territory, and social iniquity
}

\author{
1 Departamento de Saúde \\ Comunitária, Universidade \\ Federal do Ceará \\ Fortaleza, Brasil. \\ 2 Centro de Pesquisas Aggeu \\ Magalhães, Fundação \\ Oswaldo Cruz, Recife, Brasil. \\ Correspondência \\ L. G. S. Augusto \\ Departamento de Saúde \\ Coletiva, Centro de Pesquisas \\ Aggeu Magalhães, \\ Fundação Oswaldo Cruz. \\ Av. Professor Moraes Rego s $/$, \\ Cidade Universitária, \\ Recife, $P E$ \\ 50670-420, Brasil. \\ giraldo@cpqam.fiocruz.br
}

\begin{abstract}
The present paper deals with the subject of socio-environmental injustice in Brazil as a consequence of the country's current development model in the context of globalization and from the perspective of social struggle. Over time the realization of the development ideology has introduced profound changes in the country's territory, with severe repercussions for population and ecosystem health that have only recently been included on the social agenda. Efforts to reconcile solutions to the social and environmental crises have converged in the concept of sustainable development, within new discourses in the field of collective health (and whose analysis provides the point of departure for this paper). Territory is explored as a useful tool for analyzing the relationship between health, environment, and development, revealing the paradox between Brazil's great natural and human potential and its poverty, reflecting environmental injustice and disregard for human rights. This expanded concept of territorial organization is important for understanding the context of modernization and the possibility for poor populations to enjoy a better life.
\end{abstract}

Sustainable Development; Social Inequity; Enviromental Health
Raquel Maria Rigotto 1

Lia Giraldo da Silva Augusto 2

\section{Desenvolvimento, sustentabilidade e (in)justiça ambiental}

"Sucumbir" foi o verbo utilizado pelo Massachusetts Institute of Technology ${ }^{1}$ para dizer o que aconteceria se todos os países do mundo continuassem em sua política de crescimento: sucumbir à poluição do meio ambiente, ou à exaustão dos recursos naturais, ou ao custo elevado de controle da poluição. Isso foi no início dos anos 1970, sucedendo ao desastre ecológico na Baía de Minamata, no Japão, contaminada por efluentes líquidos industriais contendo mercúrio, em que adoeceram e morreram pescadores e moradores. Entre outros episódios...

"Na história da humanidade, foi um momento crítico de encontro entre a sólida ideologia do desenvolvimento e a emergente consciência ambiental. De um lado, esta sesquicentenária significação imaginária social, que cresce e se expande junto com a burguesia, a partir do século XIV. Envolvendo as idéias de racionalidade, economia, progresso, expansão $e$ crescimento, ela institui a crença de que o objetivo central da vida humana éo crescimento ilimitado da produção e das forças produtivas" 2 (p. 156). Fortalecendo-se junto com o capitalismo, a noção de desenvolvimento vem a se constituir numa utopia da sociedade moderna ou "crença da religião moderna", no dizer de Rist ${ }^{3}$.

De outro lado, as transformações ambientais produzidas na relação sociedade-natureza 
- e suas implicações para a saúde, por exemplo - começam a se configurar como problemas na agenda sócio-política internacional: eles passam a ser construídos como tal e difundidos no mundo social por vários atores sociais, buscando o reconhecimento por um conjunto amplo de indivíduos e instituições 4,5 .

Evidentemente, desde a Grécia Clássica ou a Idade Média, as atividades humanas sobre o meio - as obras hidráulicas no Egito, o crescimento da urbis romana, a expansão cristã na Europa - despertaram, em alguma medida, indagações sobre os efeitos destas atividades sobre o entorno. Entretanto, a realização histórica do capitalismo toma a dimensão de uma verdadeira revolução técnica e social, repercutindo, em escala e abrangência inéditas, em todos os aspectos da vida das sociedades ocidentais modernas, inclusive o trabalho, a saúde e o ambiente. Promove-se uma ruptura do Sujeito com a Natureza - quando a técnica passa a intermediar uma relação de dominação e exploração, a partir da emergência do pensamento racional positivo e laico sobre a natureza ${ }^{6}$. Mascara-se, assim, a profunda e dinâmica inserção dos seres humanos no ambiente e a interdependência entre eles, abrindo-se as portas simbólicas para agredi-lo.

Novos traços surgem nesta sociedade: novos tipos de consumo; obsolescência planejada dos produtos; um ritmo cada vez mais rápido de mudanças na moda e no estilo; a difusão da cultura do automóvel; a penetração da propaganda, da televisão e dos meios de comunicação em geral, num grau até então sem precedentes em toda a sociedade 7 . Na mesma linha, Altvater 8 afirma que o moderno sistema industrial capitalista depende de recursos naturais numa dimensão desconhecida a qualquer outro sistema social na história da humanidade, além de contaminar água, ar e solos. Até mesmo os problemas criados pelas relações de produção e consumo das sociedades são transformados em oportunidades de negócios, e são inventadas soluçõesmercadorias: água potável engarrafada, joggings e academias, os diversos produtos das indústrias da segurança e da despoluição: medicamentos, prisões etc. 9,10. Configura-se assim a questão ambiental, derivada do “... predominio casi hegemónico de lo económico sobre lo social; de la economía como un fin sobre el hombre - limitado a ser considerado como recurso y/o consumidor; de las variables monetarias, fiscales y financieras sobre la producción; de lo material sobre los valores ético-morales; de la competencia y el individualismo sobre la equidad, la solidariedad y la justicia social; del consumo ilimitado sobre la satisfacción de las necesidades básicas de grandes mayorías y de las futuras generaciones; etc" 11 (p. 22).
Se, na sociedade industrial, são difundidas as crenças da fé no progresso, confiança na razão instrumental e esperança no controle dos efeitos colaterais da tecnologia, na sociedade contemporânea o progresso pode passar a ser reconhecido como a fonte de autodestruição da sociedade. Trata-se de um conjunto de riscos que ameaçam as atuais gerações, sua qualidade de vida e possivelmente as próprias condições de sobrevivência das gerações futuras, caracterizando, na alta modernidade, uma sociedade de risco, marcada pela perda de controle, a irredutibilidade, a incerteza, a invisibilidade e o desconhecimento dos riscos 12,13.

Entretanto, é necessário pontuar com Habermas 6 que se a evolução do sistema social $p a-$ rece ser determinada pelo progresso científico e tecnológico, e se este se apresenta como quase autônomo, são os interesses humanos que continuam a determinar a direção, as funções e a velocidade deste progresso. Esta dissimulação das questões não só justifica o interesse parcial de dominação de uma determinada classe e reprime a necessidade parcial de emancipação por parte de outra classe, mas também afeta o interesse emancipador como tal do gênero humano. Por trás da aparente "autonomização das forças da sociedade industrial” há a ação organizada de grupos econômicos articulados internacionalmente, exercendo a hegemonia do poder para a defesa de seus interesses de acumulação - para o que buscam se apropriar da ciência e da técnica. Seus discursos e práticas devem ser identificados e analisados, tanto para compor a teoria social como para iluminar a reflexividade da sociedade e a ação política - ou seja, a formação democrática da vontade política não perde o sentido 14 .

É exatamente no contexto social e político de confronto entre o desenvolvimentismo e a questão ambiental que se esboça a idéia de desenvolvimento sustentável, formalmente introduzida na agenda social internacional em 1987, através do Relatório Brundtland, 15 anos depois da Conferência das Nações Unidas para o Meio Ambiente Humano. Neste, o conceito interliga economia, tecnologia, sociedade e política e propõe uma nova postura ética. Aponta como medidas a serem tomadas pelos Estados Nacionais: a limitação do crescimento populacional; a garantia da alimentação em longo prazo; a preservação da biodiversidade e dos ecossistemas; a diminuição do consumo de energia; o controle da urbanização selvagem e a integração entre campo e cidades menores e a satisfação das necessidades básicas. Defende o aumento da produção industrial nos países não-industrializados à base de tecnologias ecologicamente adaptadas, colocando-o como uma retomada do crescimento, mas 
alterando a qualidade do desenvolvimento, a fim de torná-lo menos intensivo em matérias-primas e mais eqüitativo em seu impacto.

A expressão "desenvolvimento sustentável" tem se difundido amplamente na sociedade, ao tempo em que ganha em polissemia. Paralelamente, buscam-se as interligações e impactos dessa proposta com e para a saúde dos grupos humanos. Urge, portanto, aprofundar o debate em torno dessa perspectiva. Herculano 15 (p. 17), por exemplo, entende que "o desenvolvimento sustentável é proposta resultante do compromisso internacional histórico entre grupos interessados em proteção ambiental e grupos preocupados em promover uma agenda de desenvolvimento social", para encontrar uma solução integrada de duas crises simultâneas contemporâneas que se reforçam mutuamente: a crise de desenvolvimento social global e a crise ambiental global. Entretanto, considera que o termo "desenvolvimento" não é sinônimo de sociedade, e prende o debate ao campo restrito da economia, reafirmando sua hegemonia, num momento em que se propõe a superação deste reducionismo e uma subordinação do instrumental econômico a questões éticas, em benefício de uma visão mais totalizante e social. O desenvolvimento sustentável seria um desenvolvimento "suportável", distanciado da almejada "sociedade feliz" 16.

Sachs 17 também considera o desenvolvimento sustentável uma alternativa média entre o economicismo arrogante e o fundamentalismo ecológico: o crescimento econômico ainda se fazia necessário para não deteriorar ainda mais a situação da maioria pobre, mas ele deveria ser socialmente receptivo e implementado por métodos favoráveis ao meio ambiente. Sublinha que o desenvolvimento sustentável exige uma distribuição diferente da propriedade e da renda e requer algum tipo de intervenção e planejamento por parte do Estado, além de estratégias complementares entre o Norte e o Sul. Assim, lamenta que " a revolução ambiental tenha coincidido com a contra-revolução neoliberal e o ressurgimento do mito do laissez-faire" 17 (p. 63) - o que o leva a justificar a necessidade de uma eco-socioeconomia.

Afirmando que a proposta de desenvolvimento sustentável não perturba a procura do lucro nem a lógica do mercado, Veiga 18 apóiase em autores como Georgescu-Roegen e Boulding-Passet para destacar a existência de um sério conflito entre as lógicas que asseguram o desenvolvimento econômico e a reprodução da biosfera, dificultando a compatibilização entre desenvolvimento e sustentabilidade.

Altvater 8 assinala que o desenvolvimento realiza-se no espaço global, mas de modo ex- tremamente descontínuo e não simultâneo nas diversas nações e regiões do mundo. Nas relações Norte-Sul, a riqueza aumenta na mesma proporção da pobreza, e esta distância avança também em todas as sociedades nacionais: as condições globais estão em cada país, em cada cidade do mundo unificado, que é um mundo dividido. Silva 19 (p. 144-5) situa, no contexto da globalização, esta seletividade espacial: "Quando se analisa o mundo globalizado buscando-se compreender como se desenha sua distribuição espacial, é imprescindivel verificar o fenômeno da não-integração de partes significativas do globo terrestre. Trata-se de imensas áreas, com baixo nível de absorção de tecnologia, com alto grau de pobreza e subdesenvolvimento, com muita fome e miséria. Essa não-integração é um típico exemplo da seletividade espacial da globalização".

Além disso, nesse contexto, os recursos naturais, os riscos tecnológicos e ambientais gerados pelos processos de produção e consumo, e também a degradação ambiental e os agravos à saúde que causam, são distribuídos de forma desigual no espaço, entre os segmentos sociais e entre as sociedades. É o que Herculano 15 denomina de estratificação sócio-espacial, determinada numa teia complexa que articula as dinâmicas econômica, social e política, as quais geram, nomeiam, localizam, estudam, negociam, regulam, controlam, eliminam ou potencializam os riscos.

É preciso considerar ainda que a vulnerabilidade dos diversos segmentos sociais aos novos riscos desigualmente introduzidos nos territórios também não é igual. Fatores como o estado nutricional, a escolaridade, as possibilidades de acesso à informação, o grau de cobertura e a qualidade das políticas públicas, entre outros, implicam diferenças nos tipos e na extensão dos impactos dos riscos que sofrerão.

Quando os problemas ambientais são causados por fontes locais, freqüentemente suas proximidades são habitadas por grupos sociais mais pobres, enquanto os mais ricos ocupam áreas menos degradadas. À insuficiência de serviços básicos de saneamento, de coleta e destinação do lixo e condições precárias de moradia, tradicionalmente relacionadas à pobreza e ao subdesenvolvimento, somam-se a poluição química e física do ar, da água e da terra, provocando uma vasta gama de doenças e deformações congênitas.

De fato, a apropriação e distribuição dos recursos de um território são definidas em processos políticos, em que a decisão depende fortemente das disputas entre as forças sociais hegemônicas e os movimentos sociais - processos que remetem aos níveis de democratização das instituições políticas 20 . Nessa perspectiva, não é 
difícil compreender como movimentos sociais de diferentes lugares vieram a questionar a noção de igualdade entre todos os cidadãos na exposição a riscos - implícita no conceito de sociedade de risco. Ao formularem o conceito de Justiça Ambiental, esses movimentos questionam " a enorme concentração de poder na apropriação dos recursos ambientais" e as dinâmicas sociais e políticas que, em sociedades desiguais, "destinam a maior carga dos danos ambientais do desenvolvimento às populações de baixa renda, aos grupos raciais discriminados, aos povos étnicos tradicionais, aos bairros operários, às populações marginalizadase vulneráveis" 21 (p. 10).

Trata-se, antes de mais nada, de refutar a tese do mercado - produzir, consumir, crescer. E, reconhecendo que há uma ligação entre o exercício da democracia e a capacidade da sociedade se defender da injustiça ambiental ${ }^{22}$, promover princípios e práticas ${ }^{21}$ que:

a) Assegurem que nenhum grupo social, seja ele étnico, racial ou de classe, suporte uma parcela desproporcional das conseqüências ambientais negativas de operações econômicas, de decisões de políticas e de programas federais, estaduais, locais, assim como da ausência ou omissão de tais políticas;

b) Assegurem acesso justo e eqüitativo, direto e indireto, aos recursos ambientais do país;

c) Assegurem amplo acesso às informações relevantes sobre o uso dos recursos ambientais e à destinação de rejeitos e localização de fontes de riscos ambientais, bem como processos democráticos e participativos na definição de políticas, planos, programas e projetos que lhes dizem respeito;

d) Favorecem a constituição de sujeitos coletivos de direitos, movimentos sociais e organizações populares para serem protagonistas na construção de modelos alternativos de desenvolvimento, que assegurem a democratização do acesso aos recursos ambientais e a sustentabilidade do seu uso.

A idéia de sustentabilidade pode assim ser resgatada, na perspectiva de reverter as tendências degradantes do modelo hegemônico de desenvolvimento nos atuais tempos de globalização, a partir dos anseios dos diferentes grupos sociais em seus territórios.

\section{A emergência da noção do território e sua implicação para as políticas públicas}

Hoje, novos atributos definem o valor estratégico do território, rompendo a exclusividade do poder do Estado sobre o território nacional. Tal redefinição se inseriu no contexto das profun- das mudanças observadas no final do século XX e que foram decorrentes da ação conjugada de dois elementos fundamentais 23,24 .

O primeiro, a revolução técnico-científica, especialmente o desenvolvimento das biotecnologias, microeletrônica e das mídias, criando uma nova forma de produção, cujo material bruto é a informação, que se torna fonte para o ser político e da produtividade econômica 14 .

O segundo, a crise ambiental, que passou a constituir um limite real para a expansão do modelo estabelecido de produção e de compreensão do que produzir, que impõe novos padrões de relação da sociedade com a natureza, exigindo eqüidade de informação e de conhecimento 25 .

No território é possível identificar duas tendências. Na primeira, podemos observar a existência de duas tensões dominantes entre as forças produtivas: uma, a procura das vantagens do competidor inserido no território, e que não estão determinadas apenas pela tecnologia, onde o território é visto como possuidor de condições particulares relacionadas com os recursos naturais, as iniciativas políticas, a capacidade de organização e de negociação. A outra é a de introdução de um novo valor estratégico ao território, sob o discurso de revalorização dos elementos da natureza no modo de produção, especialmente útil para a inserção de novas tecnologias como as biotecnologias (exemplo: transgenia) e as matrizes energéticas (exemplo: biodiesel). Aqui, a natureza é avaliada como capital 23.

Em uma direção oposta, cresce a busca dos valores sociais e culturais presentes e da construção de uma estratégia de valoração do território, que demanda por autonomia, no qual se derivam projetos alternativos para as sociedades locais e que precisam de alianças globais mediante redes nacionais e transnacionais.

Ambas as tendências ("forças produtivas" e "forças sociais") criam uma perspectiva para uma "nova territorialidade" (estratégias que visam a influenciar a ação de controle dos territórios) e introduzem fortes diferenciações nos países, reduzindo o poder de controle do Estado sobre a dinâmica do processo produtivo e da sociedade nacional 23 .

No interior dos antagonismos, o território ganha um novo papel, atribuindo às comunidades a possibilidade de se rever diante da globalização, ampliando sua visão e sua consciência, impondo um novo pensamento do mundo onde cada país, cada lugar ou cada região possa transformar suas más condições em favor da vida.

No caso brasileiro, é o território com todos os seus lugares - cidades e campo - que denuncia a profunda crise da nação e dos males que o processo da globalização vem criando em toda 
parte. No curso dessas mudanças, a idéia do desenvolvimento sustentável aparece como a expressão e o instrumento que visa à conciliação dos conflitos, no regulamento do uso do território e no estabelecimento de uma nova sociedade-natureza, em acordo com a necessidade de uma nova forma de produção 14 .

Nesse processo estão três aspectos fundamentais: (i) eficácia, referente a uma nova racionalidade na utilização dos recursos naturais e de incorporação de informação e tecnologia nos produtos e processos; (ii) avaliação da diferença, referente à identificação e ao fortalecimento da vocação de cada território; (iii) descentralização, constituindo nova forma de governança participativa, identificada como gerência integrada do território, que incorpora a ciência, a tecnologia e as relações de poder, com uma nova relação de confiança pública 23.

A novidade do modelo chamado de "desenvolvimento sustentável” é que não pode ser automaticamente transposto para todos os lugares: é baseado nas diferenças de cada território. A conformação dos territórios por múltiplos atores em diversas escalas geográficas é resultado das complexas relações sociais existentes, da relação sociedade-natureza e também das redes de relações extralocais 24 .

O Brasil é dotado de uma fantástica fonte natural, a maior biodiversidade do planeta; de significativos avanços tecnológicos, representados por redes de junção interna e transnacional; e de importante parque industrial, o maior do hemisfério sul, posição alcançada à custa de grandes desigualdades sociais e regionais e da enorme perda de recursos naturais e de vidas humanas.

Nesse contexto, o Estado e a sociedade têm uma responsabilidade enorme sobre o território e na política territorial, que deveriam ser a base dos fundamentos principais da legitimação nacional. A gestão do território é certamente uma questão importante para a construção de sociedades justas, economicamente eficientes e não predatórias da natureza.

No território é que podemos apreender os processos e as tendências para um diagnóstico dos contextos e situações de risco social, possibilitando o monitoramento das ações executadas para sua reformulação, para a busca das parcerias intersetoriais e com os segmentos da sociedade, incorporando efetivamente o controle social das ações sobre o território.

A perspectiva e a possibilidade de uma gestão integrada no território incorpora necessariamente as políticas de ciência e de tecnologia sob a égide dos conflitos de interesse, e pode ser uma possibilidade de romper definitivamente com a herança de um padrão histórico de desenvolvi- mento baseado no autoritarismo e no conceito de progresso como ilimitado crescimento, com incorporação crescente de recursos naturais, ainda tratados na prática como infinitos.

A informação contextualizada no território é uma condição indispensável e de vital importância para a sociedade e para o Estado no processo de gestão transformadora, pois é o espaço para a ressignificação das grandes questões nacionais, capazes de afetar o trânsito das análises globais, saindo do abstrato para o concreto, à luz do reconhecimento das diferenças locais, com suas especificidades e potencialidades 24 .

Para tal, a informação não pode ser obtida por meio de exaustivos inventários desarticulados, como freqüentemente têm sido realizados, mas pela integração de dados, cuidadosamente tomados em função das demandas dos variados atores e em diferentes escalas geográficas 26 .

Cada lugar é constitucionalmente diferente do outro, por sua história e sua condição atual, mas todos demandando soluções para seus emergentes problemas, as quais raramente podem ser oferecidas apenas com medidas isoladas 24 . Por essa razão, a gestão do território poderia trabalhar com indicadores de mudanças segundo as teses e princípios presentes nas formulações da Agenda 21 ou das Cidades Saudáveis, por exemplo.

\section{O contexto da globalização no Brasil}

Para a maioria da humanidade, o processo de globalização influencia direta e indiretamente todos os aspectos da existência: da vida econômica e cultural, das relações interpessoais e da subjetividade delas decorrentes 26 .

A imposição dos princípios da globalização no contexto neoliberal tem sido um forte elemento de produção e aprofundamento das iniqüidades sociais, conseqüentemente beneficiando somente um conjunto limitado de atores, e causando danos à maioria. Sobre as condições preexistentes dos países ou como resultado do formulário que estes tiveram de adotar para participar da nova ordem mundial, os países em desenvolvimento vêm sofrendo uma grande diversidade de impactos que lhes dão características novas no contexto da nova ordem mundial.

No Brasil, onde as elites se caracterizam por um gosto ancestral pela modernidade, esse processo se evidencia fortemente no ambiente e no enfraquecimento das instituições que têm papel de protegê-lo. Sua história é uma sucessão de adesões, nem sempre confessadas, que resultaram em um processo de imitação grotesca da modernidade 25 . No Brasil foram abertos os pos- 
tulados essenciais da política econômica e social definida externamente, como os do Consenso de Washington.

Recentemente, com o neoliberalismo, há uma fragilização ainda maior da condição de nação, com a sedução de um imaginário influenciado pela forte apelação técnica e uma aceitação passiva da força totalitária da globalização.

Para uma melhor compreensão do impacto desse processo seria necessário o reconhecimento das relações sistêmicas entre as políticas em curso e os efeitos sócio-ambientais que se observam, a exemplo do aumento expressivo da morbimortalidade por causas externas decorrentes da violência, dos processos produtivos e pela pressão promovida para adoção de novos padrões de consumo.

A saúde e a qualidade do ambiente sofreram com o processo de modernização forçada, na medida que se manteve uma das piores distribuições de renda do mundo, com uma significativa população vivendo abaixo da linha da pobreza, com um baixo crescimento econômico e elevados índices de desemprego, situação que vem se agravando desde a década de 80 .

No processo do desenvolvimento brasileiro podem-se observar três aspectos geradores de iniqüidades: (i) o de uma produção artificial, com excedentes acima das necessidades; (ii) o de uma incorporação ilimitada de novos padrões de consumo nos modos de vida, sob uma racionalidade do mercado global; e (iii) o de uma produção limitada de bens essenciais acessíveis ao consumo interno 26

A forma de inserção do país nesse mercado mundializado guarda especificidades que têm aprofundado a divisão internacional do trabalho, com graves repercussões para o ambiente, o trabalho e a saúde. De fato, no Brasil, a rápida implantação da matriz industrial internacional internalizou vetores produtivos com uma forte carga de impacto sobre o meio ambiente: química-petroquímica, metal-mecânica, indústria de material de transporte, indústria madeireira, papel e celulose, e minerais não-metálicos 27 . Analisando o desenvolvimento da indústria brasileira no contexto da abertura da economia ao mercado mundializado, Schlesinger 28 registra que, nos seus dez maiores segmentos, predominam aqueles cuja produção impacta o meio ambiente de maneira significativa: produtos químicos, veículos, petróleo e coque, metalurgia, borracha e plástico, papel e celulose e têxtil. Os dados do final de 1999 confirmam o crescimento, na década, das indústrias mais intensivas em consumo de recursos naturais, acompanhado da redução da produção de bens de maior valor agregado. Barbosa 29 analisa os coeficientes de emissão de poluição industrial e conclui que a intensidade de emissões do setor exportador - especialmente o de metais pesados - é superior aos demais setores da economia brasileira. A pauta de importações, por sua vez, apresenta níveis de emissões bastante inferiores.

No campo, a expansão da fronteira agrícola vem se dando sobre e a custo da destruição de biomas nativos. Sem alterar a concentradora estrutura fundiária, expandem-se grandes empresas de monocultura sobre o Cerrado, a Amazônia, a Mata Atlântica, o Manguezal, como nos casos da soja, do eucalipto, da cana-de-açúcar e do cultivo de camarões em cativeiro - a carcinicultura. Se a dimensão da modernização se expressa pela introdução da mecanização e do uso intensivo de agrotóxicos e fertilizantes, ela traz consigo o desemprego na zona rural; a expulsão de famílias de agricultores de suas terras; a contaminação do solo, das águas, dos trabalhadores e dos consumidores dos alimentos produzidos, além da destruição dos ecossistemas de onde comunidades tradicionais secularmente obtinham seu sustento, gerando situações de grave insegurança alimentar 20 .

$\mathrm{Na}$ atualidade, reconhece-se a tendência de relocalização sócio-espacial dos processos produtivos, que estariam aproveitando as facilidades de transporte e comunicação hoje disponíveis, para reduzir os custos de produção e agregar competitividade a seus produtos, por meio do dumping social e ambiental. Os países "desenvolvidos" do hemisfério Norte - pressionados pela sociedade e pelo Estado a uma reforma ecológica - estariam exportando riscos para os países "subdesenvolvidos" ou "emergentes" do Sul. Aqueles processos mais consumidores de recursos naturais, mais geradores de poluentes e que se caracterizam por processos de trabalho mais insalubres e perigosos tenderiam a localizar-se em alguns locais: os que apresentam legislações ambientais e trabalhistas menos rigorosas; onde o aparato institucional de vigilância não tenha condições de fazer valer as políticas consensadas; em que a população e os trabalhadores estejam fragilizados pelas precárias condições de vida, e dispostos a "aceitar qualquer coisa" em troca de uma fonte de renda; onde a sociedade civil não esteja suficientemente informada e organizada para defender seus interesses 30 .

Conforma-se uma nova lógica que radicaliza e aprofunda a divisão internacional do trabalho e a distribuição sócio-espacial dos riscos ocupacionais e ambientais derivados da industrialização, ampliando, com isso, as possibilidades de dano à saúde da população e também ao ambiente, pela fragilidade dos mecanismos regulatórios vigentes nos novos contextos em que se inserem 31 . O 
mesmo processo pode ocorrer também dentro de um país, onde indústrias encerram suas atividades em alguns locais - em que os sindicatos e o movimento ecológico já se organizaram, reuniram informações sobre seus impactos negativos e pressionam os órgãos públicos para uma atuação adequada - e implantam novas unidades muitas vezes em regiões sem tradição industrial anterior 8,32 .

Nessa situação, as técnicas, a velocidade de introdução de novos padrões produtivos e de consumo e o poder real de gasto criaram necessidades e desigualdades pela impossibilidade de acesso ao que é ofertado.

O Brasil não é um país "pobre", mas tem um número extremo de pessoas pobres. Apesar de estar entre as 11 maiores economias do mundo, 53 milhões de brasileiros vivem na pobreza. Neste país enorme, 22 milhões sobrevivem na condição de miséria. De acordo com o relatório do Banco Mundial 33, o Brasil continua sendo um dos campeões das desigualdades sociais e econômicas na América Latina: 10\% dos brasileiros pobres recebem apenas $0,9 \%$ da renda do país, enquanto os $10 \%$ mais ricos ficam com $47 \%$ da renda nacional 34 .

Os dados do Censo Demográfico de 200035 dão uma melhor idéia dos contrastes quando mostram que cerca de um quarto da população assalariada $(24,4 \%)$ ganhava até um salário mínimo e 2,6\% ganhavam mais de 20 salários mínimos. No contraste regional, o Nordeste tem a maior proporção da população com renda de até um salário mínimo $(46,2 \%)$ e a menor na faixa de mais de 20 salários mínimos (1,4\%). Já o Sudeste aparece com a menor proporção de até um salário mínimo (16\%) e a mais alta de mais de 20 $(3,3 \%)$.

O Censo Demográfico demonstra que em nove anos a população brasileira passou dos $147 \mathrm{mi}$ lhões de habitantes, em 1991, para 174 milhões em 2000, representando um crescimento médio anual de 1,6\% 34. O Brasil está passando por transformações demográficas profundas, inclusive na sua estrutura etária. Em tempos recentes, há um intenso e rápido declínio da fecundidade, o maior já observado entre os países mais populosos do mundo. As modificações estruturais na composição de idade são de natureza tal que, como se deduz das estimativas da Organização das Nações Unidas, no espaço de 100 anos entre 1950 e 2050, a relação da população acima de 65 anos, inicialmente inferior 3\%, alcançará $18 \%$ ao fim deste período ${ }^{34}$.

Igualmente, uma redução profunda do contingente humano de menores de 15 anos, que era de $41,6 \%$ em 1950, foi para $28,8 \%$ em 2000 ; com uma projeção de 19,9\% para o ano de 2050, quando será considerado o quarto país com o mais intenso processo de envelhecimento da população, no período analisado ${ }^{33}$. Variações tão grandes, em um tempo tão curto, promovem importantes repercussões sobre a sociedade brasileira que precisam ser analisadas do ponto de vista da trajetória de seu desenvolvimento e da qualidade de vida da população.

As desigualdades não se expressam apenas nas faixas de renda, há dentro delas outras importantes desigualdades a serem consideradas. Em 2001, por exemplo, enquanto se estimava na população branca a proporção dos pobres em $22 \%$, na população negra esta era de $47 \% 33$.

De acordo com dados da Organização PanAmericana da Saúde 36, os valores médios dos índices nacionais relativos à saúde (morbimortalidade) escondem as grandes disparidades que existem entre áreas urbanas e rurais, entre as principais regiões, entre estados de cada região e entre os municípios de cada estado.

Um dado bastante ilustrativo da particularidade da "transição epidemiológica" brasileira é o aumento da mortalidade masculina devido às causas externas, especialmente no grupo de 1529 anos de idade, no qual concorre para este fato, em especial, o homicídio, o suicídio e os traumas decorrentes de acidentes no trânsito e de trabalho 37 . Trata-se de um fenômeno reflexo da insustentabilidade do modelo de desenvolvimento.

Outro exemplo é o fato do importante aumento da incidência de doenças respiratórias em grandes áreas urbanas, cujos principais agravos são: asma e bronquites resultantes da exposição a mudanças climáticas, a poluentes atmosféricos (da indústria e de veículos a motor) e a processos alérgicos (a agentes biológicos e produtos químicos de uso doméstico). Na análise de Sá 38 , as principais causas de internação, exceto as relacionadas com a gravidez (média nacional de cerca de $24 \%$ ), são as respiratórias (média nacional de cerca $16 \%$ ).

As condições sócio-ambientais são importantes elementos que moldam o perfil de morbimortalidade no Brasil. Alguns deles tecem suas relações causais com muita evidência, tais como: a ocupação improdutiva das terras, os problemas de infra-estrutura urbana, o modelo de organização social do trabalho, o desemprego, as migrações populacionais internas, a perda de biodiversidade, a perda de solos e a poluição ambiental de origem industrial e agrícola 39 .

A rápida urbanização do Brasil deu-se em um contexto de êxodo rural, em conseqüência da enorme concentração de terra nas mãos de poucos proprietários, realizada de forma extremamente violenta. Esse fato histórico é ilustrado pelos seguintes dados: entre 1991 e 1995, 2.500 
conflitos por posse da terra foram registrados; de 1985 a 1994 aproximadamente 1.100 camponeses foram mortos em tais conflitos (principalmente líderes dos movimentos por reforma agrária) 40 . A violência no campo tem aumentado, com os latifundiários agindo com milícias armadas contra os sem terras e indígenas, e apoiada pelo movimento ruralista organizado no Congresso Nacional. O país, atualmente, conta com dois ministérios para a agricultura: um para o agronegócio (Ministério da Agricultura, Pecuária e Abastecimento) e outro para a agricultura familiar (Ministério do Desenvolvimento Agrário), cujas políticas são contraditórias entre si.

Uma das conseqüências da modernização tecnológica da agricultura no mundo e das iniqüidades produzidas pela divisão internacional do trabalho é evidenciada pelos 3 milhões de envenenamentos humanos anuais, com aproximadamente 220 mil mortes, das quais $70 \%$ ocorrem nos países em desenvolvimento. Embora $80 \%$ dos agrotóxicos produzidos anualmente sejam usados nos países desenvolvidos 41 .

\section{O movimento social em uma nova aliança}

Até os anos 90, as bandeiras de luta dos movimentos sociais, especialmente defendidas pelos trabalhadores urbanos e rurais, praticamente não se solidarizavam com os habitantes das grandes cidades ou com grupos sociais excluídos (relativos à: raça, etnia, sexo, idade). A compreensão dos problemas ambientais como questões sociais tem oportunizado processos de novas alianças e de compreensão sistêmica das relações dos homens com sua ecologia.

A preocupação com a relação homem-natureza desponta na agenda dos movimentos sociais nas últimas duas décadas, especialmente no âmbito dos debates e das avaliações dos efeitos perversos do modelo do desenvolvimento econômico no mundo inteiro. Tais discussões têm contribuído para tornar mais compreensíveis as ligações entre os impactos das técnicas no ambiente, na saúde e na qualidade da vida.

Uma das questões mais sérias que se coloca nessa agenda é a problemática dos recursos hídricos e suas respectivas políticas públicas, na qual as entidades representativas dos trabalhadores das empresas de saneamento ambiental se aliam em defesa da eqüidade, contra a privatização, na proteção dos mananciais e para garantia da qualidade da água. O Brasil detém entre $12 \%$ e 15\% de toda água doce do planeta.

Essa aparente abundância induziu uma gestão pouco cuidadosa e uma cultura do desperdí- cio que são, em parte, responsáveis pela enorme iniqüidade social relativa ao acesso à água com qualidade e com sérias implicações para a saúde e para a sustentabilidade das bacias hidrográficas 27 . Há claramente escassez em determinadas áreas e com manifestos conflitos de interesses entre os diversos usos da água (consumo humano, agricultura, geração de energia elétrica, indústria, lazer etc.).

A Região Amazônica, por exemplo, detém aproximadamente $70 \%$ dos recursos hídricos do país e apenas $7 \%$ de sua população, tendo ainda grande possibilidade de preservação da qualidade de suas águas. Mas, nela já se observam sérios problemas, decorrentes da privatização dos serviços de abastecimento de água em Manaus, capital do Estado do Amazonas, e da contaminação química que excluem as comunidades periféricas que dependem da água dos rios para seu abastecimento.

A luta pela terra é outra questão que merece destaque no contexto brasileiro. O Movimento dos Trabalhadores Rurais Sem Terra é na atualidade o mais vigoroso movimento social organizado, no país, em torno de uma causa bem definida (a Reforma Agrária) e se caracteriza pela ocupação de terras improdutivas, contra a intensificação da concentração de terra decorrente da histórica política de exploração e expropriação no campo.

Vários outros movimentos sociais vêm assumindo a condição de sujeitos na defesa do ambiente, da saúde e da vida. São trabalhadores urbanos que lutam pelo banimento do amianto e de poluentes orgânicos persistentes, ou que criam novas formas de destinar os resíduos que produzimos; moradores de regiões metropolitanas que buscam garantir políticas adequadas de saneamento ambiental ou de moradia; comunidades ribeirinhas que defendem as terras das grandes barragens hidrelétricas; povos da Amazônia que também tentam proteger a floresta dos madeireiros, garimpeiros e especuladores 42 .

O campo epistêmico e de práticas em saúde e ambiente, pelas próprias características de seu objeto, vem sendo convidado a intensificar o diálogo com todas estas dimensões: as conexões e incertezas nos processos de adoecimento e morte, a construção de políticas que sustentem a necessária transversalidade; a interlocução dinâmica com a sociedade e seus movimentos, na perspectiva da superação das injustiças sócioambientais.

\section{Conclusão}

De acordo com Santos 23, o mundo de hoje permite uma outra percepção da história, por meio 
de um universo empírico. Sua dialética abriu o lugar para a utopia e a esperança. São as condições históricas do presente, sob um olhar integrador do processo de globalização, que possibilitarão reconhecer, nos lugares e na totalidade do planeta, o que existe e o que é possível ser alcançado.

Por exemplo, a racionalidade da divisão internacional do trabalho, que é mantida a ferro e fogo, de forma radical e com normas implacáveis, é contraposta pela necessidade de se ampliar e misturar o nacional com o intercontinental, de integrar os povos entre si, considerando suas diferenças raciais, de tradições e de religiões.

A combinação dessas tendências opostas, iniciada há pouco mais de meio século, que se traduz como uma nova colonização tecnológica do norte sobre o sul, afetando profundamente as economias nacionais e as relações sociais no interior e entre os países, cria novos cenários nos quais a questão ambiental propicia formas de resistência inusitadas na história da humanidade.

\section{Resumo}

As autoras apresentam uma abordagem das iniqüidades sócio-ambientais no Brasil, decorrentes do modelo de desenvolvimento, no contexto atual da globalização, e as perspectivas da luta social. A realização histórica da ideologia do desenvolvimento tem implicado em profundas transformações do território, com sérias repercussões sobre a saúde das populações e dos ecossistemas, as quais apenas muito recentemente começam a ser reconhecidas como problemas na agenda social. A tentativa de conciliar soluções para a crise social e a crise ambiental resultou na formulação da proposta de desenvolvimento sustentável - incorporada em alguns novos discursos no campo da saúde coletiva - cuja análise crítica é o ponto de partida deste artigo. O território foi examinado como um operador útil para analisar a expressão da ligação entre saúde, ambiente e desenvolvimento, revelador do paradoxo entre as potencialidades naturais e humanas do Brasil e sua pobreza, espelho da injustiça ambiental e da violação de direitos humanos. Trata-se de um conceito expandido de ordenação territorial, importante para criar a possibilidade de se compreender o contexto de modernização e de possibilidade das populações pobres conquistarem uma vida melhor.

Desenvolvimento Sustentável; Iniqüidade Social; Saúde Ambiental
Construir as redes sociais com aqueles que estão à margem dessas tecnologias, que não dependem dela, que têm maior grau de liberdade, de autonomia local, de maior flexibilidade e adaptabilidade às circunstâncias da vida, é uma possibilidade que vem sendo buscada e que observamos na realização dos Fóruns Sociais Mundiais e nas diversas redes de direitos humanos, de justiça ambiental etc.

Observamos que os locais que ainda apresentam a maior biodiversidade são aqueles considerados os mais pobres, o que faz desta constatação uma perspectiva importante de aliança para a construção da sustentabilidade, pois há nesses territórios o que se preservar para as atuais e futuras gerações. E isso tem sido alvo de disputas, onde os elementos da natureza são os verdadeiros conflitos de interesses que se apresentam na atualidade, a exemplo do agro-negócio e dos transgênicos frente o da agricultura familiar e da produção orgânica.

\section{Colaboradores}

As autoras trabalharam em conjunto na elaboração e revisão das sucessivas versões do artigo. 


\section{Referências}

1. Massachusetts Institute of Technology. Limits of growth. http://web.mit.edu (acessado em 18/ Jul/2006)

2. Castoriadis C. Reflexões sobre o "desenvolvimento" e a "racionalidade". In: Castoriadis C, organizador. As encruzilhadas do labirinto II - os domínios do homem. Rio de Janeiro: Editora Paz e Terra; 1987. p. 134-58.

3. Rist G. Le developpment - histoire d'une croyance occidentale. Paris: Presses de Sciences; 1996.

4. Tábara JD. La percepció dels problemes de medi ambient. Barcelona: Beta Editorial; 1996.

5. Freitas CM. Problemas ambientais, saúde coletiva e ciências sociais. Ciênc Saúde Coletiva 2003; 8:137-50.

6. Habermas J. Técnica e ciência como ideologia. Lisboa: Edições 70; s.d.

7. Jameson F. Pós-modernismo: a lógica cultural do capitalismo tardio. São Paulo: Editora Ática; 1996.

8. Altvater E. O preço da riqueza - pilhagem ambiental e a nova (des)ordem mundial. São Paulo: Editora Unesp; s.d.

9. Stahel AW. Capitalismo e entropia: os aspectos ideológicos de uma contradição e a busca de alternativas sustentáveis. In: Cavalcanti C, organizador. Desenvolvimento e natureza: estudos para uma sociedade sustentável. São Paulo: Cortez Editora; 1995. p. 104-27.

10. Rattner H. Globalização: em direção a um mundo só? In: Becker B, Miranda M, organizadores. A geografia política do desenvolvimento sustentável. Rio de Janeiro: Editora UFRJ; 1997. p. 127-48.

11. Organización Panamericana de la Salud/Organización de los Estados Americanos/Programa de las Naciones Unidas para el Desarrollo/Programa de las Naciones Unidas para el Medio Ambiente/Banco Interamericano de Desarrollo/Banco Mundial. Américas en armonía - la salud y el ambiente en el desarrollo humano sostenible. Washington DC: Organización Panamericana de la Salud; 1995

12. Giddens A, Beck U, Lash S. Modernização reflexiva - política, tradição e estética na ordem social moderna. São Paulo: Editora Unesp; 1997.

13. Giddens A. As conseqüências da modernidade. São Paulo: Editora Unesp; 1991.

14. Rattner H. Liderança para uma sociedade sustentável. Globalização versus ação local. Tecnologia e desenvolvimento para todos? A busca de um modelo alternativo. São Paulo: Editora Nobel; 1999.

15. Herculano S. Apresentação. In: Herculano S, Porto MFS, Freitas CM, organizadores. Qualidade de vida e riscos ambientais. Niterói: Editora da UFF; 2000. p. 7-16.

16. Herculano S. Do desenvolvimento (in)suportável à sociedade feliz. In: Goldenberg $\mathrm{M}$, organizador. Ecologia, ciência e política. São Paulo: Revan; 1992. p. 9-47.

17. Sachs I. Pensando sobre o desenvolvimento na era do meio ambiente. In: Sachs I, organizador. Caminhos para o desenvolvimento sustentável. Rio de Janeiro: Editora Garamond; 2000. p. 47-64.
18. Veiga JE. A insustentável utopia do desenvolvimento. In: Lavinas L, Carleial L, Nabuco R, organizadores. Reestruturação do espaço urbano e regional no Brasil. São Paulo: Editora Hucitec; 1993. p. 149-69.

19. Silva B. Cidadania, lugar e globalização. In: Valença MM, Gomes RCC, organizadores. Globalização e desigualdade. Natal: A.S. Editores; 2002. p. 136-51.

20. Leroy JP, Acselrad H, Herculano S, Pádua JA, Bertucci AA, Schilesinger S, et al. Tudo ao mesmo tempo agora - desenvolvimento, sustentabilidade, democracia: o que isso tem a ver com você? Petrópolis: Editora Vozes; 2002.

21. Rede Brasileira de Justiça Ambiental. Declaração de princípios. In: Acselrad H, Herculano S, Pádua JA, organizadores. Justiça ambiental e cidadania. Rio de Janeiro: Editora Relume-Dumará; 2004. p. 13-20.

22. Acselrad H. Justiça ambiental - ação coletiva e estratégias argumentativas. In: Acselrad H, Herculano S, Pádua JA, organizadores. Justiça ambiental e cidadania. Rio de Janeiro: Editora Relume-Dumará; 2004. p. 26-39.

23. Santos M. A urbanização brasileira. 3a Ed. São Paulo: Editora Hucitec; 1996.

24. Santos M. Técnica, espaço, tempo: globalização e meio técnico-científico informacional. 2a Ed. São Paulo: Editora Hucitec; 1996.

25. Leff E. La pedagogía del ambiente. In: Leff E, organizador. Educación en ambiente para el desarrollo sustentable. México DF: Escuela Pedagógica y Sindical "Marina Vilte"; 1998.

26. Santos M, Souza MAA, Silveira ML. Prefácio. In: Santos M, Souza MAA, Silveira ML, organizadores. Território: globalização e fragmentação. São Paulo: Editora Hucitec/Associação Nacional de Pósgraduação e Pesquisa em Planejamento Urbano e Regional; 1994.

27. Santos TCC, Câmara JBD, organizadores. GEO Brasil 2002 - perspectivas do meio ambiente no Brasil. Brasília: Edições IBAMA; 2002.

28. Schlesinger S. Indústria no Brasil: produção sustentável, consumo democrático. Rio de Janeiro: Projeto Brasil Sustentável e Democrático/Federação de Órgãos para Assistência Social e Educacional; 2001.

29. Barbosa F. Impactos do comércio internacional na poluição industrial brasileira [Monografia de Bachareladol. Rio de Janeiro: Instituto de Economia, Universidade Federal do Rio de Janeiro; 1998.

30. Rigotto RM. O "progresso" chegou. E agora? As tramas da (in)sustentabilidade e a sustentação simbólica do desenvolvimento [Tese de Doutorado]. Fortaleza: Programa de Pós-graduação em Ciências Sociais, Universidade Federal do Ceará; 2004.

31. Porto MFS, Freitas CM. Socio-political amplification of chemical accidents in industrializing countries. Risk Anal 1996; 16:19-29.

32. Mol APJ. A globalização e a mudança dos modelos de controle de poluição industrial: a teoria da modernização ecológica. In: Herculano S, Porto MFS, Freitas CM, organizadores. Qualidade de vida e riscos ambientais. Niterói: Editora da UFF; 2000. p. 267-80. 
33. Negri B, Giovanni DI, organizadores. Radiografia da saúde. São Paulo: Instituto de Economia, Universidade Estadual de Campinas; 2001.

34. Programa das Nações Unidas para o Desenvolvimento Humano no Brasil/Instituto de Pesquisa Econômica Aplicada/Fundação João Pinheiro. Atlas de desenvolvimento humano do Brasil. Brasília: Programa das Nações Unidas para o Desenvolvimento Humano no Brasil/Instituto de Pesquisa Econômica Aplicada/Fundação João Pinheiro; 1998.

35. Instituto Brasileiro de Geografia e Estatística. Censo 2000. Brasília: Instituto Brasileiro de Geografia e Estatística; 2001.

36. Organização Pan-Americana da Saúde. As condições de saúde no Brasil - subsídios para elaboração do capítulo brasileiro do documento "As condições de saúde das Américas”. Brasília: Organização Pan-Americana da Saúde; 1998. (Publicação Científica, 569).

37. Carvalho EMF, Lessa F, Gonçalves FR, Silva JAM, Lima MEF, Melo Júnior W. O Processo de transição epidemiológica e iniqüidade social: o caso de Pernambuco. RASPP Rev Assoc Saúde Pública Piauí 1999; 1:107-19.
38. Sá DA. Avaliação da universalidade do acesso à saúde através dos sistemas de informações assistenciais do SUS-Brasil, 1995 e 1998 [Monografia de Conclusão de Residência]. Recife: Centro de Pesquisas Aggeu Magalhães, Fundação Oswaldo Cruz; 1999.

39. Augusto LGS, Câmara VM, Carneiro FF, Câncio J, Gouveia N. Saúde e ambiente: uma reflexão da Associação Brasileira de Pós-graduação em Saúde Coletiva. Rev Bras Epidemiol 2003; 6:87-94.

40. Terra. Mortos pela terra. http://noticias.terra.com. br/brasil/interna (acessado em 22/Mai/2004).

41. Stedile JP. A questão agrária no Brasil. São Paulo: Editora Atual; 1997.

42. Porto MFS. Saúde pública e (in)justiça ambiental no Brasil. In: Acselrad H, Herculano S, Pádua JA, organizadores. Justiça ambiental e cidadania. Rio de Janeiro: Editora Relume-Dumará; 2004. p. 11940 .

Recebido em 01/Set/2006

Aprovado em 10/Out/2006 